\title{
Validation of the ability of ESER score to predict recurrent stroke: a meta-analysis
}

\section{Type}

Research paper

\section{Keywords}

meta-analysis, ischaemic stroke, recurrent stroke, risk prediction, ESER

\begin{abstract}
Introduction

A risk stratification model is pretty important to prevent the recurrent stroke for ischemic stroke patients. The present study aimed to meta-analysis the ability of Essen Stroke Risk Score (ESRS) to accurately predict recurrence of ischemic stroke.

Material and methods

Studies on the diagnostic performance of Essen Stroke Risk Score in predicting recurrent stroke were searched by electronic and manual methods. Quality pooled C-statistics, and $95 \%$ confidence intervals $(95 \% \mathrm{Cl})$ were evaluated.
\end{abstract}

\section{Results}

Fifteen studies with a total of 94,052 patients were included in the meta-analysis. The pooled Cstatistics of ESER for patients without atrial fibrillation (AF) experiencing recurring strokes at 90-day or one-year were $0.65(95 \% \mathrm{Cl}: 0.58-0.73)$ and 0.57 (95\% Cl: $0.53-0.60)$, and the heterogeneity was weak. The average ratio of one-year recurrent stroke in the low-risk and high-risk groups classified according to ESRS is $5.6 \%$ (range 1.4 to $12.1 \%$ ) and $9.2 \%$ (range 3.2 to $20.1 \%$ ), respectively. And the calibration analysis showed the pooled RR in the low-risk group is $0.88(95 \% \mathrm{Cl}$ : 0.24-3.19) and 0.88 (0.24-3.31) with wide confidence intervals and high levels of heterogeneity, indicating the calibration ability was low.

\section{Conclusions}

ESRS had low to moderate ability to predict recurrence of stroke in patients with ischemic stroke and low calibration ability, which need to be further improved. 


\title{
Validation of the ability of ESER to predict recurrent stroke: a meta-analysis
}

\begin{abstract}
Purpose: A risk stratification model is pretty important to prevent the recurrent stroke for ischemic stroke patients. The present study aimed to meta-analysis the ability of Essen Stroke Risk Score (ESRS) to accurately predict recurrence of ischemic stroke.

Methods: Studies on the diagnostic performance of ESRS in predicting recurrent stroke were searched by electronic and manual methods. Quality pooled C-statistics, and 95\% confidence intervals $(95 \% \mathrm{CI})$ were evaluated.

Results: Fifteen studies with a total of 94,052 patients were included in the meta-analysis. The pooled C-statistics of ESER for patients without atrial fibrillation (AF) experiencing recurring strokes at 90-day or one-year were 0.65 (95\% CI: 0.58-0.73) and 0.57 (95\% CI: 0.53-0.60), and the heterogeneity was weak. The average ratio of one-year recurrent stroke in the low-risk and high-risk groups classified according to ESRS is 5.6\%(range 1.4 to $12.1 \%$ ) and $9.2 \%$ ( range 3.2 to $20.1 \%$ ), respectively. And the calibration analysis showed the pooled RR in the low-risk group is 0.88 (95\%CI: $0.24-3.19)$ and $0.88(0.24-3.31)$ with wide confidence intervals and high levels of heterogeneity, indicating the calibration ability was low.
\end{abstract}

Conclusion: ESRS had low to moderate ability to predict recurrence of stroke in patients with ischemic stroke and low calibration ability, which need to be further improved.

Key words: ESRS; Ischaemic stroke; Meta-analysis; Recurrent stroke; Risk prediction 


\section{Introduction}

Stroke is a disabling disease that imposes social burdens. Patients who have experienced cerebral ischemic events are at high risk for recurrent stroke[1,2,3]. Since the introduction of antihypertensive, lipid lowering, and antiplatelet therapies over 20 years ago, the rate of recurrence has been declining [4,5]. Therefore, identifying those at highest risk should help to optimize secondary prevention, So an effective risk stratification model for recurrent stroke is essential for ischemic stroke patients.

The Essen Stroke Risk Score (ESRS) was developed for use in the CAPRIE study and validated externally[6,7], and is now widely used in clinical practice. The ESRS takes into account predictors such as age, hypertension, diabetes mellitus, previous myocardial infarction (MI), other cardiovascular diseases, atrial fibrillation (AF), peripheral artery disease (PAD), smoking, and previous TIA or stroke. The ESRS identifies two risk categories: low (score 0-2) and high (score 3 or greater). Many studies have demonstrated the capability of the ESRS to predict recurrent stroke in ischemic stroke patients[8,9,10].

However, studies on the effectiveness of the ESRS were restricted with differences in study endpoint, follow-up time, region, and populations, and demonstrated that the ESRS had different predictive accuracy in different situations. Therefore, the scope and predictive ability of ESRS needs further research. The aim of our meta-analysis was to determine the accuracy of ESRS for predicting recurrent stroke in ischemic stroke patients. 


\section{Methods}

\section{Study selection}

Inclusion criteria were: i) research aimed at the predictive or calibration abilities of the ESRS scoring system; ii) cohort study; iii) patients with ischemic stroke; v) primary endpoint was recurrent stroke; and vi) C-statistics and 95\% confidence intervals were available.

Exclusion criteria were: i) patients had cardioembolic stroke aetiology; ii) primary endpoint was cardiovascular event; iii) study focused on self-evaluation of the ESRS; iv) paper was a review or repeated data; and v) data were incomplete and the researchers could not be contacted.

\section{Literature search}

We searched the Cochrane Library Search databases, PubMed and Embase for studies published between January 1, 2009 and March 30, 2019 using the key words "ESRS" or "Essen stroke risk score".

\section{Data extraction and quality assessment}

The quality of selected studies was independently assessed by two researchers. Any disagreements were resolved by consensus or another reviewer. The quality assessment was based on the method proposed by McGinn et al.[11]. The basic line of included studies, the C-statistics, and 95\% CIs were collected. C-statistics revealed the score's ability to discriminate between experimental variables; a C-statistic > 0.5 was considered statistically significant; a score of $0.5-0.7=$ low value, $0.7-0.9=$ medium, and $>0.9=\operatorname{high}\left[{ }^{12},{ }^{13}\right]$. We then summarized the number of recurrent strokes in different risk stratifications as categorized by ESRS. 


\section{Consistency test}

The heterogeneity between the studies was examined by the $I^{2}$ value; $I^{2}<25 \%$ means low heterogeneity, 25-50\% means intermediate, and > 50\% means high. A fixed effects model was applied when two or more studies showed homogeneity $\left(I^{2}<50 \%\right)$, otherwise, a random effects model was used, the Consistency test based on the method proposed by Wang L et al[14]. Consistency testing was performed by STATA 15.1 software.

\section{Discrimination of ESRS}

STATA 15.1 was performed to pooled the C-statistics of the ESRS scores. 90-day, one-year and five-year follow-up results were analyzed.

\section{Calibration of the ESRS}

The observed number of recurrent strokes in different ESRS stratifications in the selected studies were compared to the predicted number. The predicted number of recurrent strokes for each stratum was calculated by the observed number of each stratum of the validation study, multiplied by the recurrent stroke risk rate which derived in the original ESRS trial. Result is presented as relative $\operatorname{risk}(\mathrm{RR})$ with a $95 \% \mathrm{CI}$ for each stratum of the ESRS score. $\mathrm{RR}=1$ indicates a good calibration between the observed and predicted result, $R R>1$ indicates the ESRS under-predicts the risk of endpoint, RR $<1$ indicates the ESRS over-predicts the risk of endpoint[15]. Calibration analysis was performed by Review Manager 5.2 software (Oxford, England).

A sensitivity analysis was performed by comparing the fixed and random effects models. The degree of asymmetry was tested by an Egger's test to evaluate the publication bias. 


\section{Results}

\section{Literature selection}

135 articles were initially selected, 32 publications were remained after screening for titles and abstracts. 15 of these 32 articles were included after reviewing the full-text (Figure 1). Tables 1 \& 2 show the basic information and quality assessment of included studies.

\section{Predicting ability}

Table 3 summarized of C-statistics for different study populations and follow-up times. The heterogeneity test showed $\mathrm{I}^{2}$ in most of the groups was $<50 \%$ (Table 4 ). The pooled $\mathrm{C}$-statistic of ESER or 90-day and one-year recurrent stroke for patients without atrial fibrillation (AF) were

0.65 (95\% CI: $0.58-0.73$ ) and 0.57 (95\% CI: 0.53-0.60), respectively. For studies including patients with AF, the pooled C-statistics of ESER score for 90-day and one-year recurrent stroke were 0.56 (95\% confidence interval [CI]: 0.48-0.64 and 0.61 (95\% CI: 0.59- 0.63). The one-year pooled C-statistic of ESRS scores in studies excluding AF was similar to that of studies including $\mathrm{AF}(\mathrm{P}=0.07)$

\section{Calibration ability}

For studies without patients with AF, the average ratio of one-year recurrent stroke in the low-risk and high-risk group based on ESRS was 5.6\% (ranging from $3.1-12.4 \%$ ) and 9.2\% (from 3.2 - 20.1\%), which were similar to the figures in the original ESRS study. In studies without $\mathrm{AF}$, the average ratio of recurrent stroke based on ESRS score stratum was similar to studies containing AF. The calibration analysis result showed ESER did not significantly under 
or overestimate the observed risk of one-year recurrent stroke in each stratum; the pooled RR in the low-risk group is 0.88 (95\%CI: 0.24-3.19) and 0.88 (0.24-3.31) for the high-risk group $(\mathrm{RR}=0.88, \mathrm{P}>0.05)$ (Figure 2). However, the results should be interpreted cautiously due to wide confidence intervals of the RRs value and high levels of heterogeneity.

Sensitivity and bias analysis

The fixed and random effects models in each group showed similar results without significant differences (data not shown), which meant good stability. Egger's tests showed there was no publication bias (Table 3).

\section{Discussion}

Predictive capability of ESRS

Recurrent stroke is an independent risk factor for poor prognosis[25]. In order to reduce recurrence of strokes, it is necessary to identify high-risk patients and make appropriate therapeutic decisions. At present, many clinical scoring models, including ESRS, ABCD2 and Stroke Prognosis Instrument SPI-II, are used to assess the risk of recurrence. ABCD2 has shown good predictive ability for recurrent stroke in the short-term for TIA patients[26,27]. Compared with $\mathrm{ABCD} 2$, ESER is more easy to calculate and more widely apply in clinical practices, for which do not consist any of imaging data such as brain MRI or carotid ultrasound. The components of SPI-II risk score are similar to ESER, but SPI-II is mainly aimed at predicting recurrent stroke or death within two-years in stroke patients, ESRS is primarily used to predict in one-year follow up[28,29,30]. However, our analysis showed ESRS score was capable of predicting recurrent stroke, but the pooled C-statistics for one-year recurrence was 0.57, indicating low accuracy. In addition, we found that the ESRS was more accurate at the 90-day 
follow-up compared to one-year follow-up, possibly because recurrent stroke occurred more in the first 90 days follow-up.

However, because there are too many potential confounding factors, the predictive ability of a score model based on clinical characteristics will not be highly accurate. Ling et al. reported that by including points for hypertension $>15$ years, diabetes $>10$ years, IS/TIA, and the stroke subtype by large artery atherosclerosis, the ability of the original ESRS to predict recurrent stroke within one year was improved; C-statistics of ESRS and modified ESRS were 0.58 and 0.70[24]. Stahrenberg et al. showed that hsTropT increased the C-statistic of ESRS score from 0.695 (ESRS) to 0.747 (ESRS+hsTropT) in patients with acute cerebral ischemia[31]. Sumi et al. showed it could improve the discriminatory ability of the modified ESRS by adding a few more variables such as gender, waist circumference, and stroke subtype[17]. However, it is suitable to incorporate too many clinical factors into a scoring system, otherwise, it is too complicated to use widely in clinical practice.

Atrial fibrillation (AF) was not included in the original ESRS and it is recommended patients with AF not use ESRS to predict recurrence[6]. However, we found that the one-year pooled C-statistic of ESRS score in studies without AF was even slightly higher than that of studies containing AF, which meant some patients in the study had AF and some did not have AF. The average incidence of recurrence in ESRS score stratum in studies excluding patients with AF was similar to that of studies containing patients with AF. Previous studies have shown that atrial fibrillation has not been identified as an independent risk factor [32,33], so we believe that the ESRS system may be extended to stroke patients with a history of AF.

\section{Calibration capability of ESRS score}


A excellent score model not only shows good predictive ability, but also good calibration ability, which means the predictive result can be repeated. The present study showed that the scope of prevalence of one-year recurrent stroke in included studies without AF was a wide of range, specially the incidence in Meng 2010' study was significantly higher than Weimar 2009' and Chen 2016' study. For the reason that, Meng 2010' study was carried out in China, in contrast that Weimar 2009' study validated in western population. It has been proved that the overall proportion of ischemic stroke appeared higher in Chinese than white populations owing to race and region[34]. In other way, Chen 2016' study also came from China, but which focused on outpatients in Beijing(capital of China), so the incidence was lower than Meng 2010' study owing to social, economic and environmental conditions[35]. The incidence of recurrence in one-year follow-up ranged from $3.1-12.4 \%$ for the low-risk ESRS score group and $3.2-20.1 \%$ for the high-risk group. However, our results showed the incidence of the endpoints by ESRS score increased with the risk stratification in each included study. The calibration analysis showed a certain calibration accuracy between the predicted and observed rate of recurrence in each risk strata of the ESRS score. However, the calibration analysis also showed wide confidence intervals of the pooled RRs and high levels of heterogeneity between the included studies, so the results should be interpreted cautiously.

\section{Limitations}

Firstly, most of the included studies were retrospective (although original data were acquired prospectively), and many selected studies failed to specify whether blinding procedure was taken appropriately. Secondly, the total numbers of the included studies are low and the analysis of calibration capability showed high levels of heterogeneity, so the results of calibrating ability 
should be interpreted very cautiously. A large-scale prospective research focusing on calibration ability is thus warranted.

\section{Conclusion}

Our results demonstrated that ESRS had minimal discrimination ability in predicting recurrent stroke in patients with ischemic stroke and it seemed the ESRS was also suitable to predict for patients with AF. The calibration ability of ESRS needs further verification.

\section{Funding}

None

\section{Disclosure statement}

The authors declare no conflict of interest.

\section{Acknowledgements}

Not applicable. 


\section{Reference}

1 Davis SM, Donnan GA. Clinical practice. Secondary prevention after ischemic stroke or transient ischemic attack. N Engl J Med 2012;366:1914-1922.

2 Giles MF, Rothwell PM. Risk of stroke early after transient ischaemic attack: a systematic review and meta-analysis. Lancet Neurol 2007;6:1063-1072.

3. Feng W, Hendry RM, Adams RJ. Risk of recurrent stroke, myocardial infarction, or death in hospitalized stroke patients. Neurology 2010;74:588-593.

4 Hosomi N, Kitagawa K, Nagai Y, et al. Desirable Low-Density Lipoprotein Cholesterol Levels for Preventing Stroke Recurrence: A Post Hoc Analysis of the J-STARS Study (Japan Statin Treatment Against Recurrent Stroke). Stroke.2018(4):865-871.

5 Zonneveld TP, Richard E, Vergouwen MD, et al. Blood pressure-lowering treatment for preventing recurrent stroke, major vascular events, and dementia in patients with a history of stroke or transient ischaemic attack. Cochrane Database Syst Rev. 2018,19;7

6 CAPRIE Steering Committee. A randomized, blinded, trial of clopidogrel versus aspirin in patients at risk of ischaemic events (CAPRIE).Lancet 1996; 348:1329-1339.

7 Weimar C, Goertler M, Röther J, et al. Predictive value of the Essen Stroke Risk Score and Ankle Brachial Index in acute ischaemic stroke patients from 85 German stroke units. J Neurol Neurosurg Psychiatry. 2008;79(12):1339-1343 
8 Weimar C, Benemann J, Michalski D, et al German Stroke Study Collaboration. Prediction of recurrent stroke and vascular death in patients with transient ischemic attack or nondisabling stroke: a prospective comparison of validated prognostic scores. Stroke. 2010,41(3):487-493.

9. Weimar C, Diener HC, Alberts MJ, et al. The Essen stroke risk score predicts recurrent cardiovascular events: a validation within the Reduction of Atherothrombosis for Continued Health (REACH) registry. Stroke 2009; 40:350-354

10 Maier IL, Bauerle M, Kermer P, et al. Risk prediction of very early recurrence, death and progression after acute ischaemic stroke. Eur J Neurol. 2013(4):599-604.

11 McGinn TG, Guyatt GH, Wyer PC et al. Users' guides to the medical literature: XXII: how to use articles about clinical decision rules. Evidence Based Medicine Working Group. JAMA. 2000;284(1):79-84.

12 Ma CC, Duan CC, Huang RC, et al. Association of circulating cystatin C levels with type 2 diabetes mellitus: a systematic review and meta-analysis[J]. Arch Med Sci, 2019, 16(3).

13 Consolato Sergi, Bonnie Chiu, Joseph Feulefack, et al. Usefulness of resveratrol supplementation in decreasing cardiometabolic risk factors comparing subjects with metabolic syndrome and healthy subjects with or without obesity: meta-analysis using multinational, randomised, controlled trials, Arch Med Sci Atheroscler Dis.2020,30;5:e98-e111

14 Wang L, Zhang C, Song Y, et al. Serum vitamin D deficiency and risk of gestational diabetes mellitus: a meta-analysis[J]. Arch Med Sci, 2020, 16(4). 
15 Keogh C, Wallace E, Dillon C, et al. Validation of the CHADS2 clinical prediction rule to predict ischaemic stroke. A systematic review and meta-analysis. Thromb Haemost. 2011;106(3):528-538.

13. Fitzek S, Leistritz L, Witte OW, et al The Essen Stroke Risk Score in one-year follow-up acute ischemic stroke patients. Cerebrovasc Dis 2011, 31:400-407.

14. Ay H, Gungor L, Arsava EM, et al: A score to predict early risk of recurrence after ischemic stroke. Neurology 2010, 74:128-135

15. Chandratheva A, Geraghty OC, Rothwell PM: Poor performance of current prognostic scores for early risk of recurrence after minor stroke. Stroke 2011, 42:632-637.

16. Meng X, Wang Y, Zhao X, et al: Validation of the Essen Stroke Risk Score and the Stroke Prognosis Instrument II in Chinese patients. Stroke 2011, 42:3619-3620.

17. Sumi S, Origasa H, Houkin K, et al: A modified Essen stroke risk score for predicting recurrent cardiovascular events: development and validation. Int J Stroke2013, 8:251-257.

18. Weimar C, Siebler M, Brandt T, et al. Vascular risk prediction in ischemic stroke patients undergoing in-patient rehabilitation - insights from the investigation of patients with ischemic stroke in neurologic rehabilitation (INSIGHT) registry. Int J Stroke. 2013;8(7):503-509.

19. Liu J, Li M, Liu J. Evaluation of the ESRS and SPI-II scales for short-term prognosis of minor stroke and transient ischemic attack. Neurol Res. 2013;35(6):568-572.

20. Andersen SD, Gorst-Rasmussen A, Lip GY, et al. Recurrent Stroke: The Value of the CHA2DS2VASc Score and the Essen Stroke Risk Score in a Nationwide Stroke Cohort. Stroke. 2015;46(9):2491-2497. 
21. Chen P, Liu Y, Wang Y, et al. A Validation of the Essen Stroke Risk Score in Outpatients with Ischemic Stroke.J Stroke Cerebrovasc Dis. 2016 ;25(9):2189-2195.

22. Liu Y, Wang Y, Li WA, et al. Validation of the Essen Stroke Risk Score in different subtypes of ischemic stroke. Neurol Res. 2017;39(6):504-508.

23. Li H, Zhang R, Liu G, et al. External Validation of Pooled Cohort Risk Equations to Predict 1-Year Clinical Outcome in Ischemic Stroke Patients. Med Sci Monit. 2017;23:4415-4421.

24. Ling X, Yan SM, Shen B, et al. A modified Essen Stroke Risk Score for predicting recurrent ischemic stroke at one year. Neurol Res. 2018(3):204-210.

25. Oza R, Rundell K, Garcellano M. Recurrent Ischemic Stroke: Strategies for Prevention. Am Fam Physician. 2017;96(7):436-440.

26. Rothwell PM, Giles MF, Flossmann E, et al. A simple score (ABCD) to identify individuals at high early risk of stroke after transient ischaemic attack. Lancet. 2005;366(9479):29-36.

27. Wardlaw JM, Brazzelli M, Chappell FM et al. ABCD2 score and secondary stroke prevention: meta-analysis and effect per 1,000 patients triaged.Neurology. 2015;85(4):373-380.

28. Kernan WN, Horwitz RI, Brass LM, et al. A prognostic system for transient ischemia or minor stroke. Ann Intern Med. 1991;114(7):552-557.

29. Navi BB, Kamel H, Sidney S, et al. Validation of the Stroke Prognostic Instrument-II in a large, modern, community-based cohort of ischemic stroke survivors. Stroke. 2011(12):3392-3396.

30. Diener HC, Ringleb PA, Savi P. Clopidogrel for the secondary prevention of stroke. Expert Opin Pharmacother 2005;6:755-764. 
31 Stahrenberg R, Niehaus CF, Edelmann F, et al: High-sensitivity troponin assay improves prediction of cardiovascular risk in patients with cerebral ischaemia. J Neurol Neurosurg Psychiatry 2013, 84:479-487.

32 Kernan WN, Viscoli CM, Brass LM, et al. The stroke prognosis instrument II (SPI-II) : A clinical prediction instrument for patients with transient ischemia and nondisabling ischemic stroke. Stroke 2000;31:456-462.

33 Hankey GJ, Slattery JM, Warlow CP. Transient ischaemic attacks: which patients are at high (and low) risk of serious vascular events? J Neurol Neurosurg Psychiatry,1992;55:640-652.

34 Tsai C F, Thomas B, Sudlow C L M . Epidemiology of stroke and its subtypes in Chinese vs white populations: a systematic review.[J]. Neurology, 2013, 81(3):264-272.

$35 \mathrm{Wu}$ X, Zhu B, Fu L, et al. Prevalence, Incidence, and Mortality of Stroke in the Chinese Island Populations: A Systematic Review[J]. Plos One, 2013, 8. 
、

\section{Figure legend}

Figure 1. Flow diagram of the process of study selection. 
Figure 2. The forest plot of the calibration analysis

Note: $R R=1$ indicates a good calibration between the observed and predicted result. A relative risk $(\mathrm{RR})>1$ indicates the ESRS under-predicts the risk of endpoint, $\mathrm{RR}<1$ indicates the ESRS over-predicts the risk of endpoint. 
Table 1. The basic characteristics of included studies

\begin{tabular}{|c|c|c|c|c|c|c|c|c|c|c|c|}
\hline Study & $\begin{array}{c}\text { Country or } \\
\text { region }\end{array}$ & $\begin{array}{c}\text { Type of } \\
\text { study } \\
\text { P/R }\end{array}$ & Data original & $\begin{array}{c}\text { Sample } \\
\text { size }\end{array}$ & $\begin{array}{l}\text { Age } \\
(y r)\end{array}$ & $\begin{array}{c}\text { Males } \\
(\%)\end{array}$ & $\begin{array}{c}\text { Follow-up } \\
\text { time }\end{array}$ & Endpoint & $\begin{array}{c}\text { Excluding } \\
\text { AF }\end{array}$ & randomized & Population \\
\hline Weimar 2008[7] & Germany & $\mathrm{P}$ & SCALA & 852 & 67.1 & 57 & $17.5 \mathrm{~m}$ & RS & No & No & IS /TIA \\
\hline Weimar 2009[8] & Germany & $\mathrm{P}$ & REACH & 15605 & 68.9 & 59.6 & $1 \mathrm{yr}$ & $\mathrm{RS}$ & No & No & IS /TIA \\
\hline Weimar 2010[9] & Germany & $\mathrm{P}$ & - & 1897 & 56 & 67.7 & $1 \mathrm{yr}$ & RS & No & No & IS/TIA \\
\hline Fitzek 2010[13] & Germany & $\mathrm{P}$ & - & 730 & 73.1 & 49.1 & $1 \mathrm{yr}$ & RS & No & No & IS /TIA \\
\hline Ay 2010 [14] & USA & $\mathrm{R}$ & - & 1458 & $72-74$ & 53.7 & $90 \mathrm{~d}$ & RS & No & No & IS /TIA \\
\hline $\begin{array}{c}\text { Chandrathera } \\
2011 \text { [15] }\end{array}$ & UK & $\mathrm{R}$ & $\begin{array}{c}\text { Oxford vascular } \\
\text { study }\end{array}$ & 1247 & 73 & 54 & $90 \mathrm{~d}$ & RS & Yes & No & IS /TIA \\
\hline Meng 2011[16] & China & $\mathrm{P}$ & CNSR & 11384 & - & 63.4 & $1 \mathrm{yr}$ & $\mathrm{RS}$ & Yes & No & IS /TIA \\
\hline Sumi 2012 [17] & Japan & $\mathrm{P}$ & $\begin{array}{l}\text { EVEREST } \\
\text { registry }\end{array}$ & 3292 & $70-71$ & 67.2 & $1 \mathrm{yr}$ & RS & No & No & IS \\
\hline Weimar 2012 [18] & Germany & $\mathrm{P}$ & INSIGHT & 1163 & 66.3 & 57.5 & $13 \mathrm{~m}$ & RS & No & No & IS /TIA \\
\hline Liu 2013 [19] & China & $\mathrm{P}$ & CHANCE & 167 & 61.1 & 71.3 & $90 \mathrm{~d}$ & $\mathrm{RS}$ & Yes & No & minor IS / TIA \\
\hline $\begin{array}{c}\text { Andersen } \\
2015[20]\end{array}$ & Danish & $\mathrm{R}$ & $\begin{array}{l}\text { Nationwide } \\
\text { Danish cohort }\end{array}$ & 42182 & 70.1 & 54.3 & $1 \mathrm{yr}, 5 \mathrm{yr}$ & RS & Yes & No & IS /TIA \\
\hline Chen 2016[21] & China & $\mathrm{P}$ & ROOTS & 3316 & 64.8 & 59.6 & $3,6,12 \mathrm{~m}$ & RS & Yes & No & IS/TIA(outpatients) \\
\hline Liu 2017 [22] & China & $\mathrm{P}$ & BOSS & 1699 & 62 & 69.2 & $1 \mathrm{yr}$ & $\mathrm{RS}$ & Yes & No & IS \\
\hline Li 2017[23] & China & $\mathrm{P}$ & CNSR & 8287 & 63.2 & 63.1 & $1 \mathrm{yr}$ & RS & No & No & IS /TIA \\
\hline Ling 2018 [24] & China & $\mathrm{P}$ & - & 773 & 66 & 69.7 & $1 \mathrm{yr}$ & $\mathrm{RS}$ & No & No & IS \\
\hline
\end{tabular}

Abbreviations: $\mathrm{RS}=$ recurrent stroke; IS=ischemic stroke; TIA= transient ischemic attack; $\mathrm{AF}=$ atrial fibrillation;NA = not available; $\mathrm{P}$

$=$ prospective $\mathrm{R}=$ retrospective; 
Table 2. Quality assessment of all included studies

\begin{tabular}{|c|c|c|c|c|c|}
\hline Study & Q1 & Q2 & Q3 & Q4 & Q5 \\
\hline Weimar et al. 2008[7] & $\mathrm{Y}$ & $\mathrm{N}$ & $\mathrm{Y}$ & $\mathrm{Y}$ & $\mathrm{U}$ \\
\hline Weimar et al 2009[8] & $\mathrm{Y}$ & $\mathrm{N}$ & $\mathrm{Y}$ & $\mathrm{Y}$ & $\mathrm{U}$ \\
\hline Weimar et al 2010[9] & $\mathrm{Y}$ & $\mathrm{N}$ & $\mathrm{Y}$ & $\mathrm{Y}$ & $\mathrm{U}$ \\
\hline Fitzek et al 2010[13] & $\mathrm{Y}$ & $\mathrm{N}$ & $\mathrm{Y}$ & $\mathrm{Y}$ & $\mathrm{U}$ \\
\hline Ay et al 2010 [14] & $\mathrm{Y}$ & $\mathrm{N}$ & $\mathrm{Y}$ & $\mathrm{U}$ & $\mathrm{U}$ \\
\hline Chandrathera 2011 [15] & $\mathrm{Y}$ & $\mathrm{N}$ & $\mathrm{Y}$ & $\mathrm{U}$ & $\mathrm{U}$ \\
\hline Meng et al 2011[16] & $\mathrm{Y}$ & $\mathrm{N}$ & $\mathrm{Y}$ & $\mathrm{Y}$ & $\mathrm{U}$ \\
\hline Sumi et al 2012 [17] & $\mathrm{Y}$ & $\mathrm{N}$ & $\mathrm{Y}$ & $\mathrm{Y}$ & $\mathrm{U}$ \\
\hline Weimar et al 2012 [18] & $\mathrm{Y}$ & $\mathrm{N}$ & $\mathrm{Y}$ & $\mathrm{Y}$ & $\mathrm{U}$ \\
\hline Liu et al 2013 [19] & $\mathrm{N}$ & $\mathrm{N}$ & $\mathrm{U}$ & $\mathrm{Y}$ & $\mathrm{U}$ \\
\hline Andersen et al 2015[20] & $\mathrm{Y}$ & $\mathrm{N}$ & Y & $\mathrm{U}$ & $\mathrm{U}$ \\
\hline Chen et al 2016[21] & $\mathrm{N}$ & $\mathrm{N}$ & $\mathrm{Y}$ & $\mathrm{Y}$ & $\mathrm{U}$ \\
\hline Liu et al 2017 [22] & $\mathrm{Y}$ & $\mathrm{N}$ & $\mathrm{N}$ & $\mathrm{Y}$ & $\mathrm{U}$ \\
\hline Li et al 2017[23] & $\mathrm{Y}$ & $\mathrm{N}$ & Y & $\mathrm{Y}$ & $\mathrm{U}$ \\
\hline Ling et al 2018 [24] & $\mathrm{Y}$ & $\mathrm{N}$ & $\mathrm{Y}$ & $\mathrm{Y}$ & $\mathrm{U}$ \\
\hline
\end{tabular}

Note: Q1: Did the included patients have different disease severities?

Q2: Did the patient selection process exhibit bias? Internal authenticity

Q3: Was the dropout rate lower than 20\%?

Q4: Was the predictor to be evaluated blinded to the endpoint events?

Q5: Were the endpoint events blinded to predictors? 
Y: Yes; N: No; U: unclear.

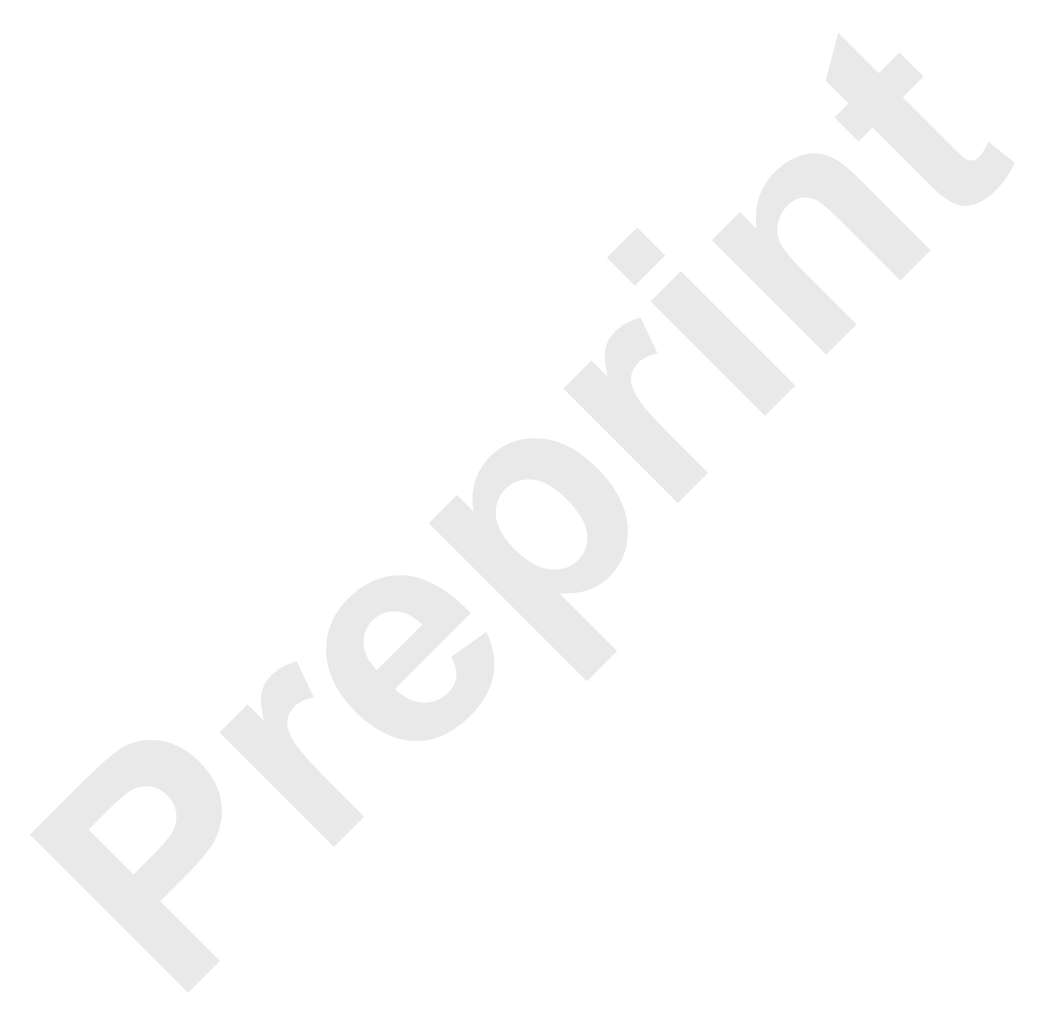


Table 3. Pooled C-statistics of ESSR score according to ninety-day and one-year follow-up time

\begin{tabular}{|c|c|c|}
\hline Follow-up time & Study & ESSR \\
\hline \multirow{3}{*}{$\begin{array}{l}\text { Ninety-day recurrent stroke } \\
\text { with patient excluding AF }\end{array}$} & Liu 2013[19] & $0.68(0.56-0.80)$ \\
\hline & Chen 2016[21] & $0.63(0.53-0.72)$ \\
\hline & Pooled C-statistic & $0.65(0.58-0.73)$ \\
\hline \multirow{3}{*}{$\begin{array}{l}\text { Ninety-day recurrent stroke } \\
\text { with patient including AF }\end{array}$} & Ay 2010[14] & $0.59(0.53-0.66)$ \\
\hline & Chandrathera 2011[15] & $0.51(0.42-0.59)$ \\
\hline & Pooled C-statistic & $0.56(0.48-0.64)$ \\
\hline \multirow{5}{*}{$\begin{array}{l}\text { One-year recurrent stroke } \\
\text { With patient excluding AF }\end{array}$} & Weimar 2009[8] & $0.56(0.53-0.58)$ \\
\hline & Meng 2011[16] & $0.60(0.57-0.61)$ \\
\hline & Andersen 2015[20] & $0.54(0.53-0.55)$ \\
\hline & Liu 2017[22] & $0.58(0.52-0.64)$ \\
\hline & Pooled C-statistic & $0.57(0.53-0.60)$ \\
\hline \multirow{8}{*}{$\begin{array}{l}\text { One-year recurrent stroke } \\
\text { With patient including AF }\end{array}$} & Fitzek 2010[13] & 0.59 (NA) \\
\hline & Weimar 2010[9] & $0.62(0.57-0.67)$ \\
\hline & Sumi 2012[17] & $0.60(0.55-0.65)$ \\
\hline & Weimar 2012[18] & $0.62(0.59-0.65)$ \\
\hline & Chen 2016[21] & $0.62(0.56-0.68)$ \\
\hline & Li 2017[23] & $0.57(\mathrm{NA})$ \\
\hline & Ling 2018[24] & $0.58(0.54-0.61)$ \\
\hline & Pooled C-statistic & $0.61(0.59-0.63)$ \\
\hline 17.5 months recurrent stroke & Weimar 2008[7] & 0.56 \\
\hline Five-year recurrent stroke & Andersen 2015[20] & $0.56(0.55-0.57)$ \\
\hline
\end{tabular}

Abbreviations: $E S R S=$ the Essen stroke risk score, $A F=$ atrial fibrillation, $C I=$ confidence interval $N A=$ not available. 


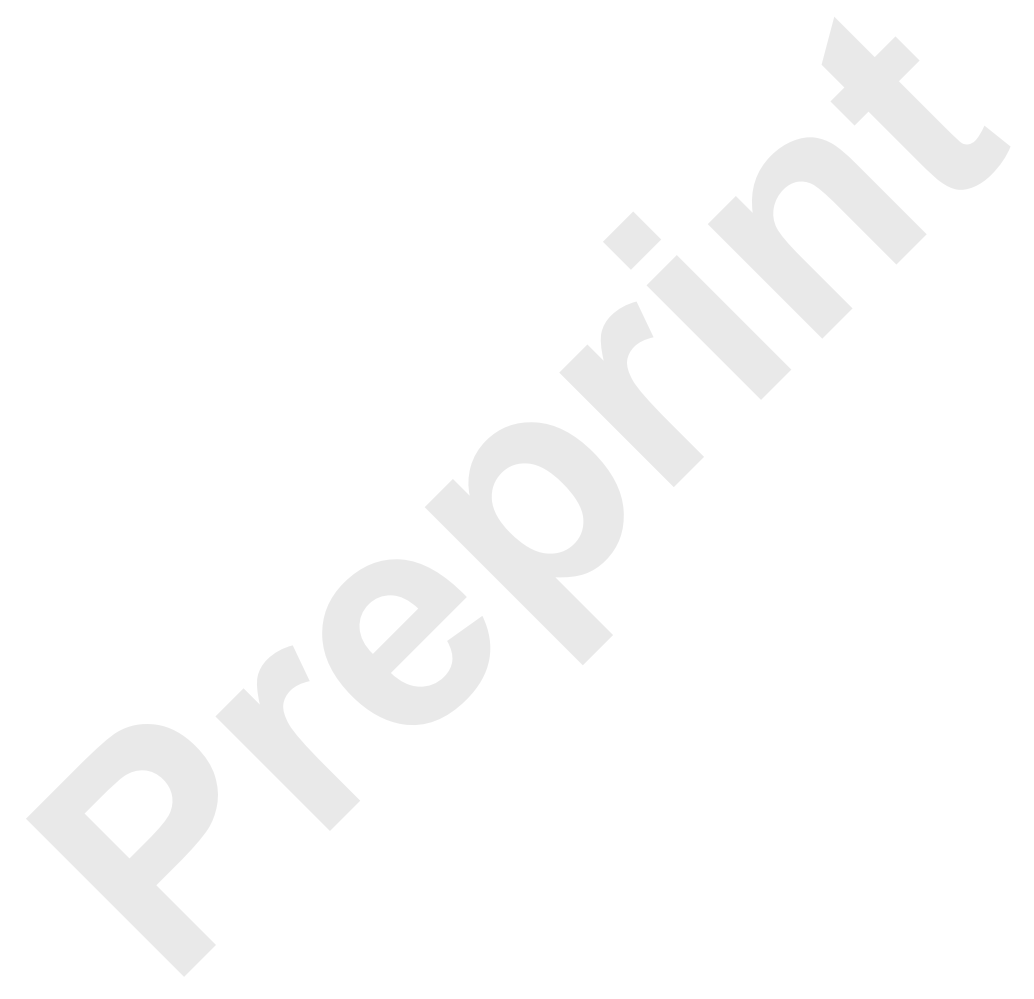


Table 4. Meta-analysis of the discrimination ability of ESRS scores

\begin{tabular}{|c|c|c|c|c|c|c|c|}
\hline \multicolumn{2}{c}{$\begin{array}{c}\text { Pooled C-statictis } \\
\text { Endpoint time }\end{array}$} & \multicolumn{2}{c}{ No. } & Heterogeneity test & Egger's test \\
\hline $\begin{array}{c}\text { Ninety-day recurrent } \\
\text { stroke with AF } \\
\text { exclusion }\end{array}$ & $0.65(0.58-0.73)$ & 2 & 0.41 & 0.52 & 0.00 & 5.95 & - \\
\hline $\begin{array}{c}\text { Ninety-day recurrent } \\
\text { stroke with AF } \\
\text { inclusion }\end{array}$ & $0.56(0.48-0.64)$ & 2 & 1.99 & 0.158 & 49.8 & -4.73 & - \\
\hline $\begin{array}{c}\text { One-year recurrent } \\
\text { stroke with AF } \\
\text { exclusion }\end{array}$ & $0.57(0.53-0.60)$ & 4 & 29.54 & 0.00 & $89.80 *$ & 3.14 & 0.43 \\
\hline $\begin{array}{c}\text { One-year recurrent } \\
\text { stroke with AF } \\
\text { inclusion }\end{array}$ & $0.61(0.59-0.63)$ & 7 & 3.4 & 0.49 & 0.00 & -0.047 & 0.98 \\
\hline
\end{tabular}

Abbreviations: $E S R S=$ the Essen stroke risk score, $A F=$ atrial fibrillation, $C I=$ confidence interval;

Note: *: a random effects model was applied $\left(I^{2}>50 \%\right)$ 
Table 5. Recurrent stroke events in ninety-day and one-year follow-up for ischaemic stroke with or without AF, n (\%)

\begin{tabular}{|c|c|c|c|}
\hline \multirow{2}{*}{ Follow-up time } & \multirow{2}{*}{ Study } & \multicolumn{2}{|c|}{ Patient(\%) } \\
\cline { 2 - 4 } & Low risk & High risk \\
\hline \multirow{3}{*}{ Ninety-day recurrent stroke } & Chandrathera 2011[15] & $21 / 236(1.6)$ & $21 / 142(17.9)$ \\
\cline { 2 - 4 } & Liu 2013[19] & $4 / 61(6.6)$ & $17 / 106(16.0)$ \\
\cline { 2 - 4 } & Average (\%) & 3.1 & 12.1 \\
\cline { 2 - 4 } & Weimar 2009[8] & $142 / 4556(3.1)$ & $482 / 11049(4.4)$ \\
\hline \multirow{3}{*}{$\begin{array}{c}\text { One-year recurrent stroke } \\
\text { With patient with AF exclusion }\end{array}$} & Meng 2011[16] & $727 / 5845(12.4)$ & $1112 / 5539(20.1)$ \\
\cline { 2 - 4 } & Chen 2016[21] & $18 / 1326(1.4)$ & $64 / 1990(3.2)$ \\
\cline { 2 - 4 } & Average. & 5.6 & 9.2 \\
\hline \multirow{3}{*}{$\begin{array}{c}\text { One-year recurrent stroke } \\
\text { With patient including AF }\end{array}$} & Weimar 2008[7] & $11 / 296(3.7)$ & $28 / 404(6.9)$ \\
\cline { 2 - 4 } & Weimar 2010[9] & $33 / 947(3.5)$ & $74 / 950(7.8)$ \\
\cline { 2 - 4 } & Fitzek 2010[13] & $19 / 269(7.1)$ & $57 / 454(12.6)$ \\
\cline { 2 - 4 } & Weimar 2012[18] & $27 / 500(5.4)$ & $31 / 356(8.7)$ \\
\cline { 2 - 4 } & Average (\%) & 4.9 & 9.0 \\
\hline
\end{tabular}

Abbreviations: $A F=$ atrial fibrillation 


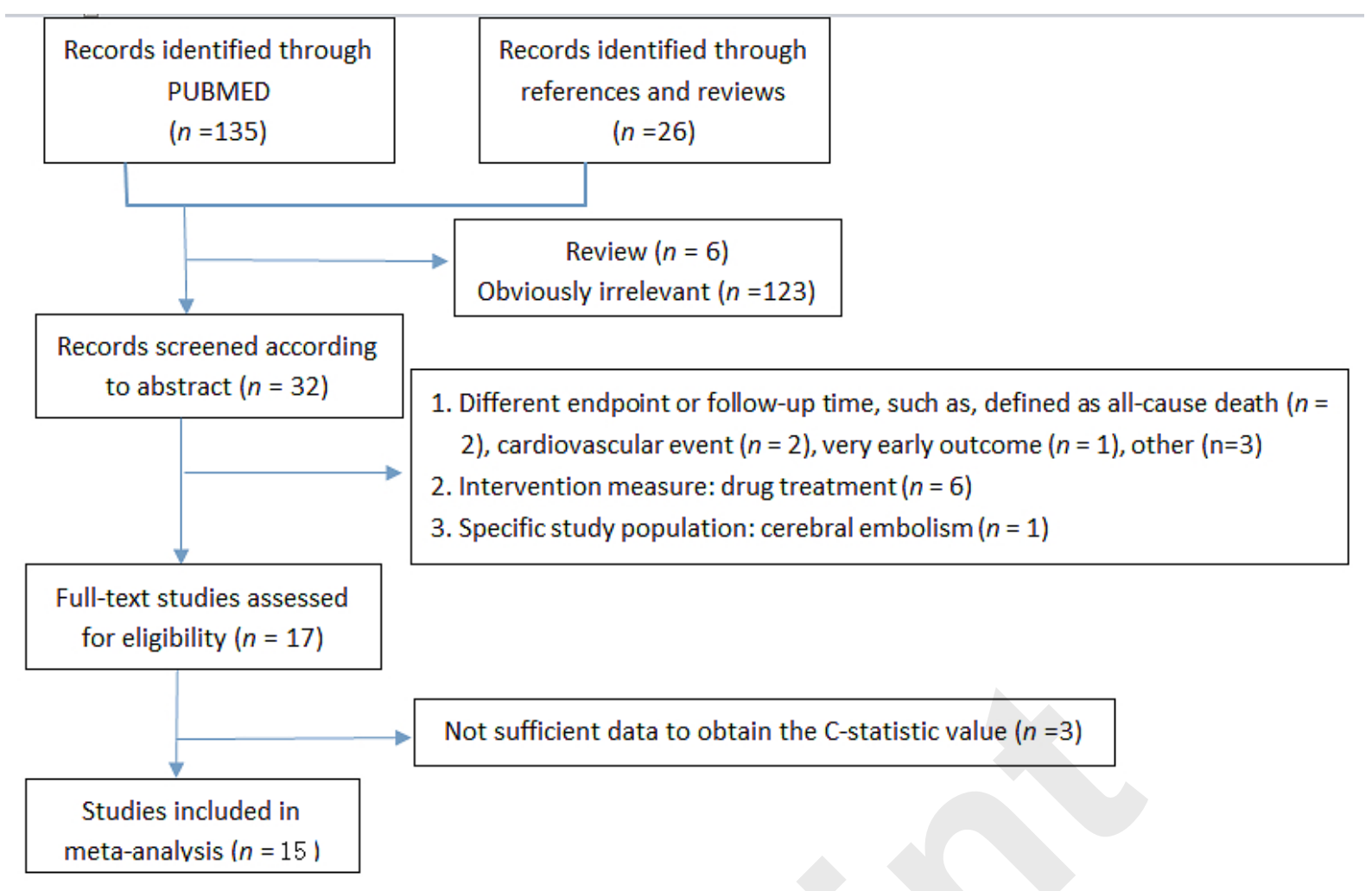




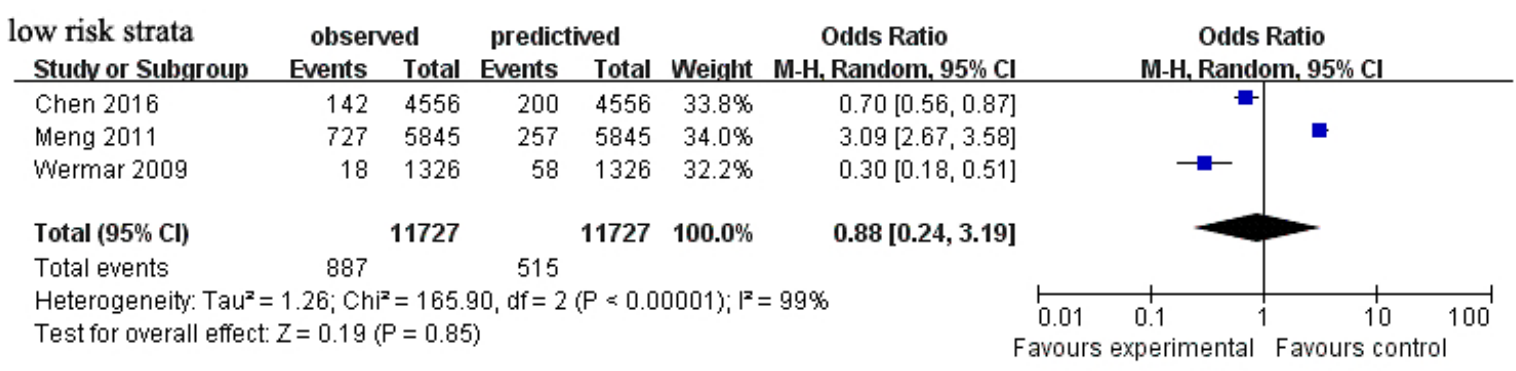

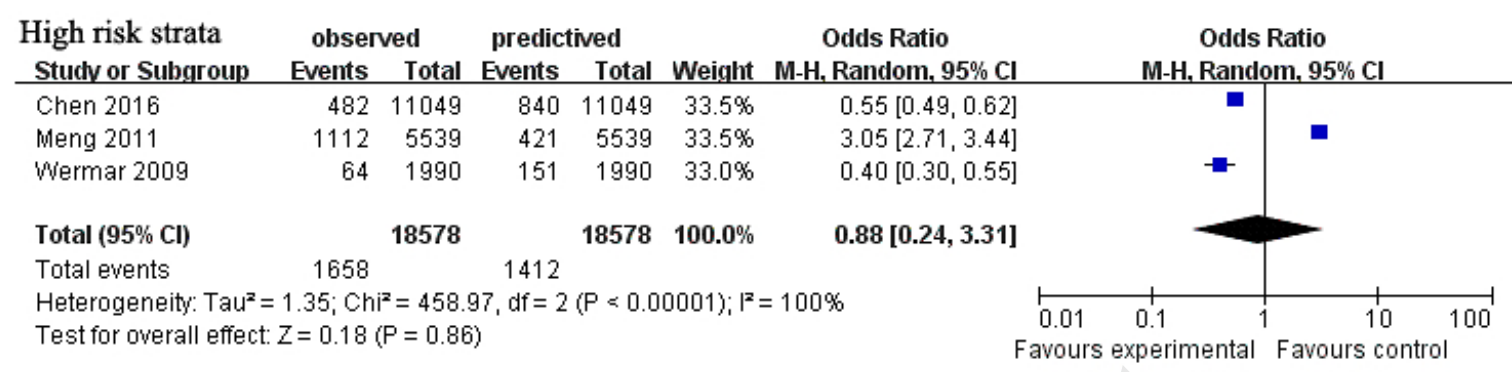

